\title{
Pirellulosomes: a new type of membrane- bounded cell compartment in planctomycete bacteria of the genus Pirellula
}

\author{
Margaret R. Lindsay, ${ }^{1}$ Richard I. Webb ${ }^{1,2}$ and John A. Fuerst ${ }^{1}$ \\ Author for correspondence: John A. Fuerst. Tel: +6173365 4643. Fax: +61733654620. \\ e-mail: fuerst@biosci.uq.edu.au
}

\author{
1 Department of \\ Microbiology, University of \\ Queensland, Brisbane, \\ Queensland 4072 . \\ Australia \\ 2 Centre for Microscopy and \\ Microanalysis, University of \\ Queensland, Brisbane, \\ Queensland 4072, \\ Australia
}

\begin{abstract}
A distinct type of cellular organization was found in two species of the planctomycete genus Pirellula, Pirellula marina and Pirellula staleyi. Both species possess two distinct regions within the cell which are separated by a single membrane. The major region of the cell, the pirellulosome, contains the fibrillar condensed nucleoid. The other area, the polar cap region, forms a continuous layer surrounding the entire pirellulosome and displays a cap of asymmetrically distributed material at one cell pole. Immuno- and cytochemical-labelling of $P$. marina demonstrated that DNA is located exclusively within the pirellulosome; cell RNA is concentrated in the pirellulosome, with some RNA also located in the polar cap region.
\end{abstract}

Keywords: bacterial ultrastructure, pirellulosomes, planctomycetes, cryosubstitution, nucleoids

\section{INTRODUCTION}

The planctomycetes are a morphologically and phylogenetically distinct division of budding organisms within the domain Bacteria defined using $16 \mathrm{~S}$ rRNA sequence analysis (Woese, 1987). They form a separate bacterial order Planctomycetales and family Planctomycetaceae (Schlesner \& Stackebrandt, 1986). The cell wall of planctomycetes does not possess peptidoglycan, an almost universal polymer of domain Bacteria members. The lack of peptidoglycan is shared only with the chlamydiae and mycoplasmas among the Bacteria (König et al., 1984; Liesack et al., 1986; Stackebrandt et al., 1986b). Their cell walls appear to be largely proteinaceous (König et al., 1984; Liesack et al., 1986; Stackebrandt et al., 1986b). Negatively stained cells display distinctive pits called crateriform structures (Tekniepe et al., 1981).

One species of planctomycete, Gemmata obscuriglobus, possesses another unique feature for a member of the domain Bacteria, a nuclear body consisting of two membranes surrounding a region containing the fibrillar DNA-containing nucleoid (Fuerst \& Webb, 1991). This body is visible after cryofixation techniques such as cryosubstitution, known to prevent artefactual membrane organelles such as mesosomes (Ebersold et al., 1981), and after freeze-fracture, as well as after conventional chemical fixation without freezing. In $G$. obscuriglobus, as in eukaryote nuclei, there are two nuclear membranes, separated by a relatively electron- transparent space. A nucleus bounded by a double membrane has been a major distinguishing characteristic between eukaryotic and prokaryotic cells, and has not been reported for any other member of the Bacteria or member of the Archaea. Because of the occurrence of cell compartmentalization in G. obscuriglobus, it was of interest to examine other planctomycete genera and species for similar types of compartmentalization, such as members of the genus Pirellula.

$P$. marina and $P$. staleyi are brackish water and freshwater representatives of the genus Pirellula of planctomycetes which display the typical planctomycete phenotype of budding reproduction, crateriform structures and proteinaceous peptidoglycan-less cell walls (Schlesner, 1986; Schlesner \& Hirsch, 1984; Liesack et al., 1986). Pirellula species differ from those of other planctomycete genera in possessing polar (rather than uniform) distribution of crateriform structures and ovoid, ellipsoidal, teardrop-like or pear-like cell shape (with one pole slightly pointed or narrower) rather than spherical cell shape (Schlesner \& Hirsch, 1984; Schlesner, 1986). The phenotypic distinction of Pirellula from other planctomycetes is correlated with their phylogenetic separation as a distinct cluster of related organisms (Stackebrandt et al., 1986a; Liesack et al., 1992; Ward et al., 1995). During the course of this investigation, it was found that Pirellula species displayed a type of compartmentalization differing in several aspects from that in G. obscuriglobus, but sharing the striking feature of membrane-bounded 
separation of genomic DNA from the rest of the cell cytoplasm.

It has been shown that the standard fixation protocol used in ultrastructural studies of planctomycetes may cause gross artefacts (Lindsay et al., 1995). In the light of this, a variety of electron microscopy techniques were employed to investigate cell compartments in Pirellula, including cryosubstitution which is known to be less subject to artefact than chemical fixation (Graham, 1992). Chemical fixation involving ruthenium red was also applied to supply supplementary structural information, as was colloidal gold-based cytochemical labelling to examine aspects of composition.

\section{METHODS}

Bacterial strains. Strain numbers used in the text are those for the Australian Collection of Micro-organisms (ACM). ATCC (American Type Culture Collection) and DSM (Deutsche Sammlung für Mikroorganismen) strain numbers are also noted here. Strains used were $P$. marina (ATCC 49060, DSM 3645, ACM 3344) and P. staleyi (ATCC 27377, ACM 3744).

Culture media and growth conditions. $P$. marina was grown on half-strength marine agar [half-strength marine broth (Difco), $1.4 \%(\mathrm{w} / \mathrm{v})$ Davis agar, autoclaved at $121{ }^{\circ} \mathrm{C}$ for $15 \mathrm{~min}$ ] or half-strength marine broth (Difco). P. staleyi was grown on caulobacter tapwater agar $(2 \mathrm{~g}$ Bactopeptone, $1 \mathrm{~g}$ yeast extract, $0.2 \mathrm{~g} \mathrm{MgSO}_{4} \cdot 7 \mathrm{H}_{2} \mathrm{O}, 10 \mathrm{~g}$ Davis agar, tapwater to $1 \mathrm{l}$, autoclaved $121^{\circ} \mathrm{C}$ for $15 \mathrm{~min}$ ). All cultures were grown for $4 \mathrm{~d}$ at $28^{\circ} \mathrm{C}$.

Phase-contrast light microscopy. To examine cells by phasecontrast light microscopy, a aliquot of cell suspension grown in half-strength marine broth was mounted under a coverslip on a block of $1 \%(w / v)$ Difco Noble agar. They were then viewed and photographed under phase-contrast employing a $\times 100$ oil immersion phase objective and Olympus $\mathrm{BH}-2$ microscope using black-and-white film (Kodak Plus-X Pan).

\section{Electron microscopy}

Ruthenium red fixation. Pirellula cultures were swabbed off plates into $1.5 \%(\mathrm{v} / \mathrm{v})$ glutaraldehyde, $0.5 \%(\mathrm{w} / \mathrm{v})$ osmium tetroxide and $0 \cdot 15 \%(\mathrm{w} / \mathrm{v})$ ruthenium red in $3 \mathrm{mM}$ HEPES buffer $\mathrm{pH} 7.0$ and fixed for $90 \mathrm{~min}$ at $4{ }^{\circ} \mathrm{C}$. Cells were washed in $3 \mathrm{mM}$ HEPES buffer for $10 \mathrm{~min}$ and enrobed in $2 \%(\mathrm{w} / \mathrm{v})$ agarose. Cells were postfixed in $0.5 \%(\mathrm{w} / \mathrm{v})$ osmium tetroxide and $0.15 \%(\mathrm{w} / \mathrm{v})$ ruthenium red in $3 \mathrm{mM}$ HEPES $\mathrm{pH} 7.0$ at $4^{\circ} \mathrm{C}$ for $1 \mathrm{~h}$. After washing in $3 \mathrm{mM}$ HEPES buffer, cells were dehydrated through a graded ethanol series and embedded in Spurr resin. Thin sections were cut on a Reichert Jung Ultracut $\mathrm{E}$ microtome and placed on pioloform-coated copper grids. Grids were stained with $5 \%(\mathrm{w} / \mathrm{v})$ uranyl acetate in $50 \%(\mathrm{v} / \mathrm{v})$ methanol for $3 \mathrm{~min}$ and then in Reynolds lead citrate for 2 min and viewed under a JEOL 1010 transmission electron microscope operated at $80 \mathrm{kV}$.

Freeze-fracture/freeze-etch. Cells were swabbed into $20 \%(\mathrm{v} / \mathrm{v})$ aqueous glycerol and left for $2 \mathrm{~h}$ at room temperature. They were frozen in liquid Freon 22 and fractured using a Balzers BAE 120 fitted with a double replica fracturing device at $-115^{\circ} \mathrm{C}$ and $10^{-7}$ torr $(1$ torr $=133 \mathrm{~Pa})$. For freeze-etch samples were fractured at $-115^{\circ} \mathrm{C}$ and etched at $-100{ }^{\circ} \mathrm{C}$ for $1 \mathrm{~min}$. Replicas were produced using platinum/carbon and stabilized with a layer of carbon, then thawed, cleaned using $3 \%$ sodium hypochlorite, washed in water and picked up on pioloform-coated grids.
Cryofixation. Cells were enrobed in $2 \%(\mathrm{w} / \mathrm{v})$ agarose placed on a square of regenerated cellulose filter paper (Sartorius) and plunge-frozen in liquid propane using a Reichert-Jung KF80 cryofixation unit.

Cryosubstitution. Two types of cryosubstitution were used. In the first, the agarose-embedded cells were cryosubstituted with $2 \%(\mathrm{w} / \mathrm{v})$ osmium tetroxide in molecular-sieve-dried acetone at $-80^{\circ} \mathrm{C}$ for $50 \mathrm{~h}$. The temperature was increased to $-20^{\circ} \mathrm{C}$ over $14 \mathrm{~h}$. Specimens were then brought to room temperature, washed in acetone, and embedded in Spurr resin, and sectioned, stained and examined as described for ruthenium red fixation. The second type of cryosubstitution was for immunolabelling studies, and involved cryosubstitution of agarose-embedded cells with $0 \cdot 2 \%(\mathrm{v} / \mathrm{v})$ glutaraldehyde in molecular-sieve-dried acetone at $-80^{\circ} \mathrm{C}$ for $50 \mathrm{~h}$. The temperature was then increased to $-20^{\circ} \mathrm{C}$ over $14 \mathrm{~h}$. Specimens were washed in acetone at $-20^{\circ} \mathrm{C}$ and embedded in Lowicryl $\mathrm{K} 4 \mathrm{M}$ at $-20^{\circ} \mathrm{C}$. Thin sections cut from blocks of Lowicryl were picked up on Formvar coated nickel grids.

\section{Immunolabelling}

$\mathrm{d} / \mathrm{ss}$ DNA. Thin sections of cryosubstituted $P$. marina on nickel grids were floated onto three drops PBS $(34 \mathrm{mM} \mathrm{NaCl}$, $0.7 \mathrm{mM} \mathrm{KCl}, 20 \mathrm{mM} \mathrm{Na}{ }_{2} \mathrm{HPO}_{4}, 0.4 \mathrm{mM} \mathrm{KH}_{2} \mathrm{PO}_{4}$, pH 7.5)/ glycine $(0.02 \mathrm{M})$ for $5 \mathrm{~min}$ each. They were then floated onto drops of primary antibody mouse $\operatorname{IgM}$ anti-ds/ssDNA (Boehringer Mannheim) diluted 1:20 in PBS/BSA (1\%) (v/v) for $1 \mathrm{~h}$. They were washed on four drops PBS/BSA and subjected to the secondary antibody, goat anti-mouse $\operatorname{IgM}$ (Sigma) diluted 1:100 in PBS/BSA for $1 \mathrm{~h}$. They were then given four 5 min PBS/BSA washes and then placed on a drop of rabbit anti-goat antibody coupled to $10 \mathrm{~nm}$ colloidal gold (British Biocell International) diluted 1:20 in PBS/BSA, for $1 \mathrm{~h}$. Grids were then given four PBS washes of $4 \mathrm{~min}$ each and four water washes of $2 \mathrm{~min}$. The grids were dried and sections stained as described above for ruthenium red fixation. A control for non-specific labelling was performed using only rabbit anti-goat colloidal gold, and a control for DNAspecificity of labelling was performed using treatment with DNAse I (10 U $\mathrm{I}^{-1}$, Boehringer Mannheim) for $3 \mathrm{~h}$ at $37^{\circ} \mathrm{C}$.

RNA. Freshly thin-sectioned cryosubstituted $P$. marina on nickel grids were floated section side down onto drops of phosphate buffered saline (PBS pH 7.5) for 5 min. Grids were floated onto RNAse-gold reagent [ribonuclease coupled to $10 \mathrm{~nm}$ colloidal gold (ICN) which had been diluted 1:1 with PBS] for $1 \mathrm{~h}$ at room temperature. Grids were then given two 5 min PBS washes and four $1 \mathrm{~min}$ washes in water. The grids were dried, stained with $5 \%(\mathrm{w} / \mathrm{v})$ uranyl acetate in $50 \%$ $(\mathrm{v} / \mathrm{v})$ methanol for $2 \mathrm{~min}$ and in Reynolds lead citrate for $1 \mathrm{~min}$. To check specificity of RNAse-gold labelling, a negative control was included using a pre-treatment of sections with $10 \mathrm{mg}$ RNAse $\mathrm{ml}^{-1}$ (Boehringer Mannheim) for $1 \mathrm{~h}$ at room temperature, which were then labelled with RNAsegold.

Statistical analysis of immunolabelling. Gold particle numbers were evaluated from 20 separate cells in micrographs of immunolabelled thin sections enlarged 70000-fold. Areas $(A)$ of the cell compartments, e.g. pirellulosome and cap, were determined by images of micrographs scanned using a video camera as input to a Wild MD30 + image analysis program, and density of labelling $\left(N_{\mathrm{s}}\right)$ calculated by the count of the number of gold particles $\left(N_{\mathrm{i}}\right)$ present over the same areas $\left(N_{\mathrm{s}}\right.$ $\left.=N_{\mathrm{i}} / A\right)$. Background densities were determined for each cell used for compartment counts from the area around the cell in each micrograph. 
Statistical analysis of labelling densities was performed as follows: for the case of comparisons between cell compartments, a one-tailed $t$-test was employed on log-transformed data, while for comparisons of RNase pre-treated RNase-gold labelled controls with cells treated with RNasegold label only, a one-tailed two-sample $t$-test for random independent samples was applied on log-transformed data.

Cytochemistry. Freshly cut thin sections of cryosubstituted cells were stained for complex carbohydrates including glycogen and glycoproteins using phosphotungstic acid according to the method of Hayat (1991) or using tannic acid/uranyl acetate according to the methods of Afzelius (1992) and Takagi et al. (1983).

\section{RESULTS AND DISCUSSION}

\section{Cell compartmentalization}

In both Pirellula species, cells processed by cryosubstitution possess two compartments, the major one of which we term here the pirellulosome (Fig. 1a, b).The pirellulosome contains the fibrillar nucleoid and also electron-dense ribosome-like particles $(9-17 \cdot 7 \mathrm{~nm}$ in diameter), resulting in the pirellulosome outside the nucleoid exhibiting the typical appearance of bacterial cytoplasm in thin sections of cryosubstituted cells. The pirellulosome is surrounded by a single double-track membrane [4.7-5.2 nm wide in P. marina (Fig. 1c) and $3 \cdot 2-4 \cdot 3 \mathrm{~nm}$ wide in $P$. staleyi]. The membrane separates this compartment from the second distinct compartment, an apparently ribosome-free region. Along the internal side of the pirellulosome membrane, ribosomelike particles appear to be arrayed in a linear manner (Fig. 1c), possibly indicating some transport of material such as newly synthesized protein across the pirellulosome membrane and between pirellulosome and polar cap region. This latter region displays a distinctive polar cap which forms its major portion in area, but which extends to form a narrow ring surrounding the pirellulosome. In this paper, the term 'polar cap region' will be used to refer to the whole nonpirellulosome compartment including the major polar area and the narrow ring area. The major polar area itself will be referred to as the 'polar cap'. The polar cap region varies in size and texture; it can be as large as a $45 \%$ of the cell volume or as small as $9 \%$. In many cells of both species (about $57 \%$ ), the polar cap appears to be filled with electron-dense material, while in others the polar cap is more electron-transparent.

The pirellulosome, which is always the major cell compartment, contains a distinct fibrillar nucleoid visible in cryosubstituted cells, in contrast to the appearance of nucleoids of other bacteria in cryosubstituted preparations, such as that found for Escherichia coli and Bacillus subtilis, where the nucleoid comprises a thin granular material rather than thin filaments (Hobot, 1985; Ryter, 1988). Also, in those bacteria, the nucleoid in cryosubstituted material is 'coralline', located in large regions with several extensions penetrating the cytoplasm; in contrast, Pirellula strains show a relatively confined fibrillar nucleoid region, as seen in Fig. 1(a,b). The folded and rippled appearance of the nucleoid in cryosubstituted cells of both Pirellula species examined (most obvious in Fig. 1a) is similar to that found in chromosomes of dinoflagellate eukaryotes, even when cryosubstituted (Kellenberger, 1991a).

It is likely that the compartmentalization observed in Pirellula species represents the situation in the living cell, since cryosubstitution is known to give rise to fewer artefacts than other conventional chemical fixation processes (Graham, 1992; Ryter, 1988). Since they are seen in cryosubstituted cells, pirellulosomes are not likely to be the product of such artefact-generating processes as those known to give rise to 'mesosomes' in chemically fixed bacterial cells (Ebersold et al., 1981; Hobot $e t$ al., 1985). The appearance of living P. marina and $P$. staley $i$ as visualized by phase-contrast microscopy is also consistent with this view. Staley (1973) in the first description of $P$. staleyi noted polar differentiation in phase-contrast microscopy preparations, where cells were frequently more transparent at their narrow poles (the pole at which the cell attaches to others in rosettes). Such polar differentiation was also observed in the present study for both $P$. staleyi and $P$. marina using phase-contrast microscopy (Fig. 1d).

The polar cap region might be interpretable as merely a large periplasm between the cell wall and the cytoplasmic membrane. This would be so if the membrane surrounding the pirellulosome was in fact the cytoplasmic membrane, and if no cytoplasmic membrane surrounded the polar cap region itself. This is made problematic partly because the cytoplasmic membrane of planctomycetes is difficult to demonstrate clearly, as is common with many other bacteria in unplasmolysed cells, but apparently exacerbated by the appression of cytoplasmic membrane to the unusual cell wall of planctomycetes. However, we have determined the presence of cytoplasmic membrane appressed to the cell wall and outside the polar cap region, on the basis of several criteria, e.g. presence of double-track membrane in favourable planes of section retracted from wall in some places but continuous with membrane appressed to wall in others (the membrane becoming distinguished in retracted areas), and occasional appearance of plasmolysed polar regions retracted from the wall indicating that the polar region is part of a cytoplasmic membrane-bounded protoplast including both polar region and internal membrane-bounded pirellulosome (Fig. 1e). In addition, the presence of RNA in the polar cap region attests to its probable cytoplasmic rather than periplasmic nature. Freeze-fracture results also confirm the presence of a plasma membrane (and certainly a cell boundary membrane outside the internal pirellulosome membrane).

\section{Ruthenium red fixation}

Major cell compartmentalization is seen in chemically fixed cells as well as cryosubstituted cells, contributing strong evidence that such compartmentalization is not induced by particular fixation protocols. Ruthenium red 

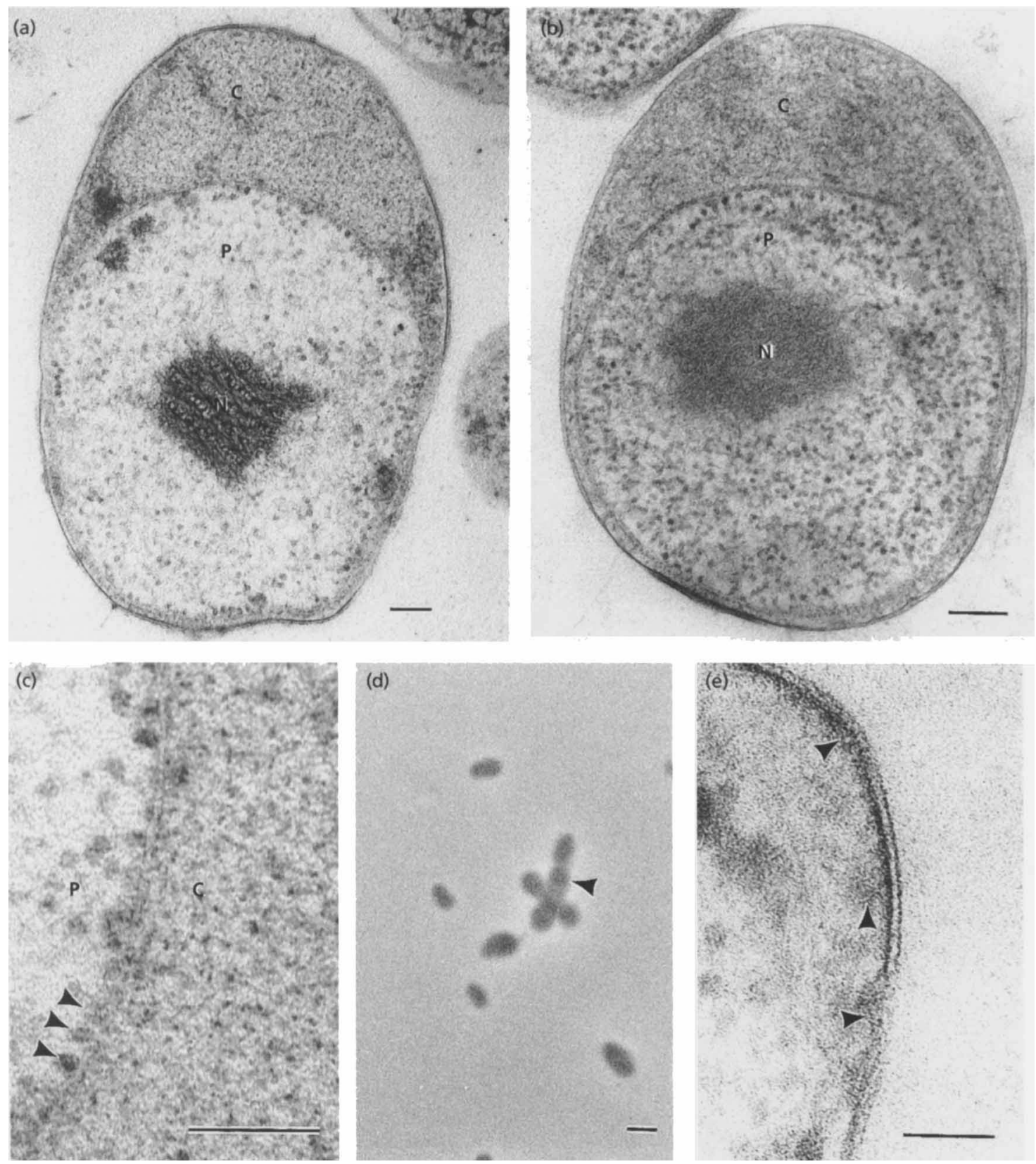

Fig. 1. Thin section of cryosubstituted cell of (a) P. marina and (b) P. staleyi displaying compartmentalization into pirellulosome $(P)$ and polar cap region (C). The pirellulosome contains a fibrillar nucleoid $(N)$. (C) An enlarged region from the cell shown in (a) showing the single double-track membrane separating the pirellulosome from the polar cap region. Ribosome-like particles (arrows) line the pirellulosome-side surface of the membrane. (d) Phase-contrast light microscopy appearance of broth-grown cells of $P$. marina displaying compartmentalization into phase-dark (arrow) and phase-light regions, seen most clearly in cells comprising the central rosette. (e) Thin section of cryosubstituted cell of $P$. marina showing areas where plasma membrane becomes visible (arrows), including one where retraction from the cell wall of the usually tightly appressed membrane has occurred (central arrow). Bars: a-c, $0.1 \mu \mathrm{m} ; \mathrm{d}, 2 \mu \mathrm{m} ; \mathrm{e}, 50 \mathrm{~nm}$.

fixation shows the polar cap as a heavily stained region within the cell (Fig. 2a); in contrast to its appearance after cryofixation, this area is only seen as a small area of the cell (mean 12-23\%). The nucleoid is very well defined as a relatively extensive region separated from the cytoplasm of the pirellulosome. It involves a large proportion (up to $50 \%$ ) of the pirellulosome, but exhibits a very distinct diffuse fibrillar structure indicative of gross nucleoid condensation, unlike cryofixation where a much less extensive region of condensed nucleoid fibrils is seen. The fibrillar condensation of the nucleoid DNA in the ruthenium-red-fixed cells is of the type expected when conventional chemical fixation is applied to typical bacterial nucleoids, in contrast to the 

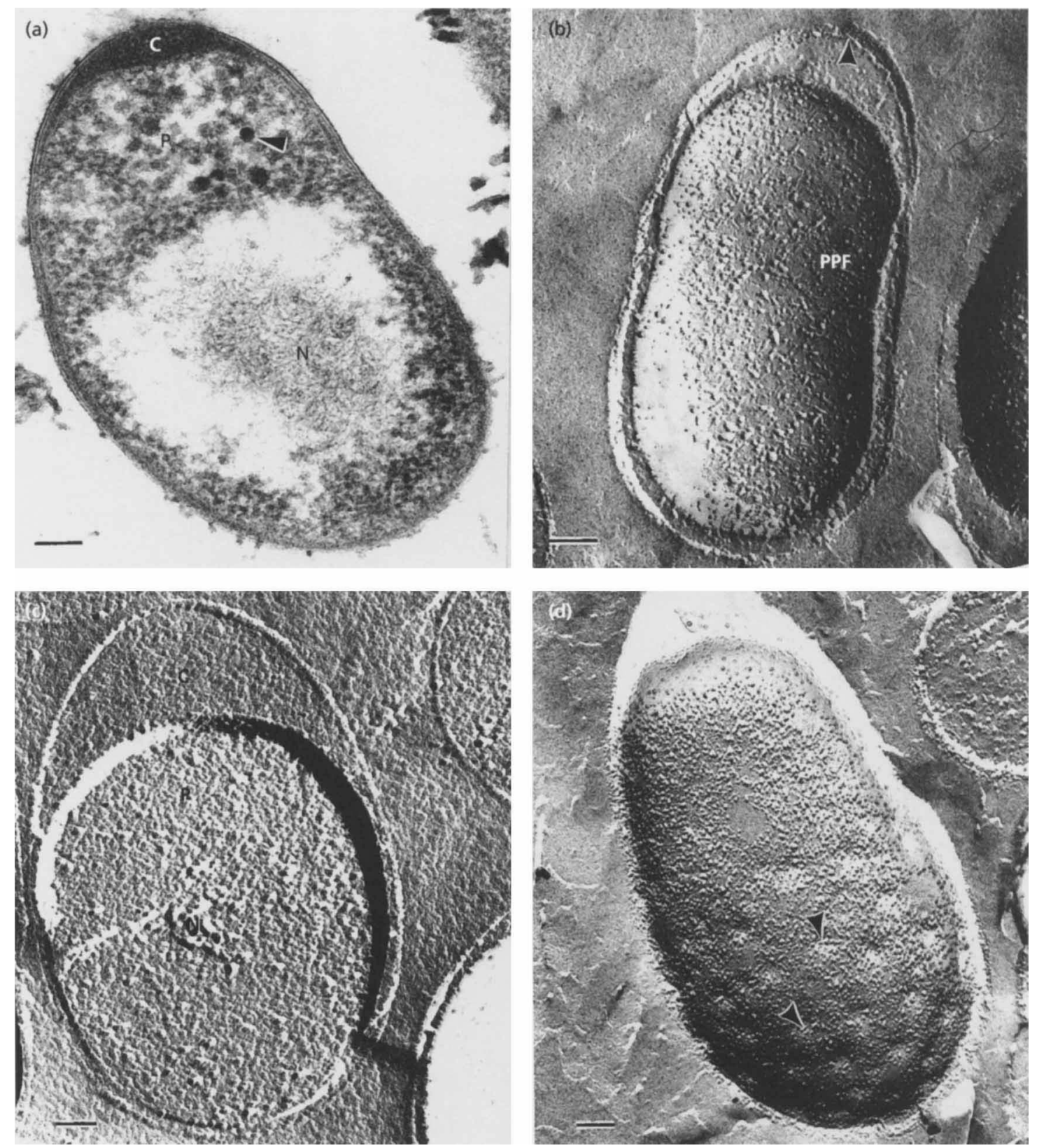

Fig. 2. (a) Thin section of ruthenium-red-fixed cell of $P$. marina showing compartmentalization of pirellulosome (P) and polar cap region $(C)$ and an extensive nucleoid region $(N)$ within the pirellulosome. Large electron-dense particles are seen within the pirellulosome towards the polar cap (arrow). (b) Freeze-fracture replica of unfixed $P$. marina showing a fracture along the pirellulosome membrane surface (PPF) revealing the outline of the pirellulosome boundaries within the cell. The plasma membrane is also visible as a separate membrane at the cell periphery (arrow). (c) Freeze-fracture replica of unfixed $P$. marina showing cross-fracture through pirellulosome and polar cap region separated by crossfractured pirellulosome membrane. The fibrillar nucleoid $(\mathrm{N})$ is also visible within the pirellulosome compartment. (d) Freeze-etch replica of glutaraldehyde-fixed $P$. marina displaying 'dimples' (arrows) in the plasma membrane, which displays a particulate fracture face. Bars, $0.1 \mu \mathrm{m}$.

granular DNA plasm of cryofixed and cryosubstituted cells as mentioned (Kellenberger, 1991a, b; Kellenberger \& Arnold-Schulz-Gahmen, 1992). There are two types of electron-dense particles present within the pirellulosome. The first type are what we identify as the cells ribosomes $(5-18 \mathrm{~nm})$. The second are larger and more electron-dense than the ribosomes $(35-52 \mathrm{~nm}$ ), and are always seen within the pirellulosome towards the cap region (Fig. 2a). Ruthenium red is known to stain mainly acid mucopolysaccharides but it is also known to stain polar lipids, proteins, glycogen and common oligosaccharides when used with osmium 

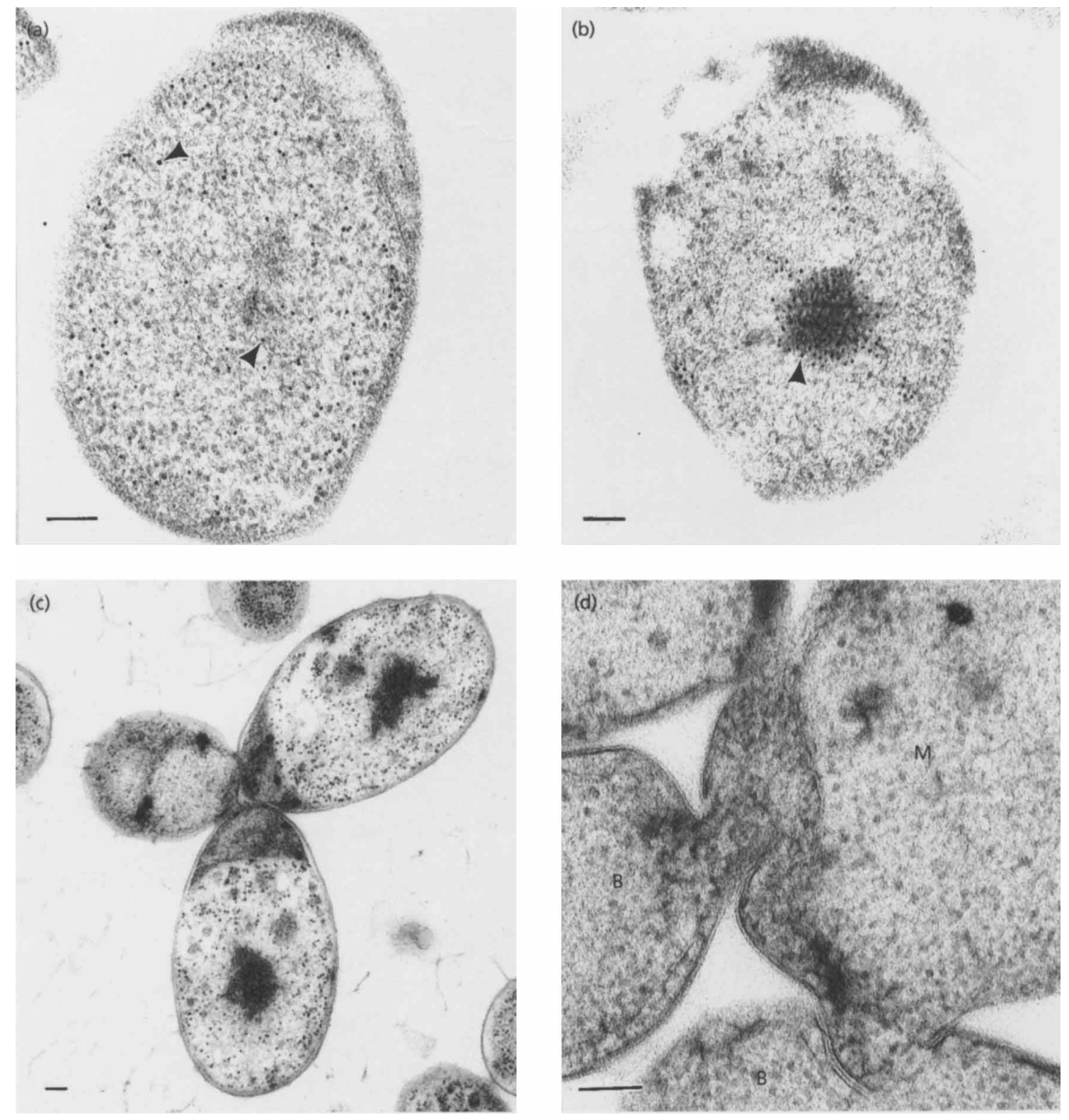

Fig. 3. Thin section of cryosubstituted $P$. marina: (a) labelled with RNase-gold, showing extensive labelling within the pirellulosome (arrows) and low labelling within the polar cap region; (b) gold-labelled using anti-ds/ssDNA antibody, showing labelling associated with the fibrillar nucleoid (arrow) within the pirellulosome; (c) showing a rosette of cells which display compartmentalization, with electron-dense polar cap regions at the rosette centre; (d) showing the centre of a rosette which may be the result of multiple budding. Two buds (B) still attached to the mother cell (M) are seen, both of which display continuity of their cytoplasm with the polar cap of the mother cell. Bars, $0.1 \mu \mathrm{m}$.

tetroxide (Hayat, 1991) (as in the present study). The heavy staining of the polar cap after ruthenium red fixation may indicate that this region is rich in polysaccharide. We cannot exclude the presence of protein or even glycoprotein in this region, however. Phosphotungstic acid or tannic acid/uranyl acetate was applied to sections to stain glycogen or glycoproteins. Although staining of polar cap was observed, it was still observed after pre-staining treatment with proteinase $\mathrm{K}$ or periodate oxidation, which are expected to prevent staining if it was due to proteins or carbohydrates, respectively.

\section{Freeze-fracture/etch}

Examination of unfixed glycerol-cryoprotected freezefractured cells confirmed the existence of a distinct polar cap region and of a membrane-bound pirellulosome in Pirellula cells. In some cases a fracture has occurred along the pirellulosome membrane surface to reveal the outline of the pirellulosome boundaries within the cell (PPF in Fig. 2b); the pirellulosome membrane is thus demonstrated to be an internal membrane with no apparent connections with the plasma membrane. We 
Table 1. RNA-gold label intensities

\begin{tabular}{|lrc|}
\hline Location & \multicolumn{2}{c|}{ Intensity (particles $\left.\boldsymbol{\mu m}^{-2} \pm \mathrm{SEM}\right)$} \\
\cline { 2 - 3 } & \multicolumn{1}{c|}{ Test } & Control \\
\hline Pirellulosome & $112 \cdot 0 \pm 6 \cdot 17$ & $8 \cdot 0 \pm 0 \cdot 93$ \\
Cap & $11 \cdot 0 \pm 1 \cdot 34$ & $6 \cdot 0 \pm 1 \cdot 14$ \\
Background & $4 \cdot 0 \pm 0 \cdot 39$ & $6 \cdot 0 \pm 0 \cdot 56$ \\
\hline
\end{tabular}

interpret the membrane fracture face at the boundary of the fractured cell in Fig. 2(b) as being the plasma membrane. The cell wall in this organism is not expected to fracture since it is proteinaceous, and would require etching to have occurred to reveal its outline. In other cases the pirellulosome could be seen in cross-fracture and a region within this cross-fracture with a texture consistent with fibrillar nucleoid was apparent (Fig. 2c). When cells are glutaraldehyde-fixed and then freezefractured/etched, a membrane surface is revealed displaying 'dimples' which are often distributed at one pole, exactly like the distribution of cell wall crateriform structures in this species (Fig. 2d). We interpret this membrane surface as that of plasma membrane, containing either scars left after the stripping or removal of crateriform structures adhering to the wall during fracture or indications of the basal structures of the crateriform structures embedded in the plasma membrane. These 'dimples' are rarely seen in fractured replicas of unfixed cells. Such fixation may alter membrane fracture properties so that plasma membrane is more easily fractured than in unfixed material. In contrast, the pirellulosome membrane appears to be more easily fractured in unfixed cells (Fig. 2b). Thus, two different methods involving cryofixation are consistent in revealing the existence of compartmentalization of the $P$. marina cell into a pirellulosome region and a polar cap region.

\section{RNAse-gold labelling and anti-ds/ssDNA antibody immunolabelling}

Using P. marina as a model, the pirellulosome compartment was shown to contain both DNA and RNA as determined from immunocytochemical labelling. Using RNAse-gold as a direct marker for RNA, RNA was found distributed predominantly within the pirellulosome, and was not always associated with ribosome-like particles (Fig. 3a). The labelling density over the pirellulosome was significantly greater $\langle P<$ $0 \cdot 001$ ) than labelling density over the polar cap region (Table 1). The polar cap itself displayed some labelling with RNAse-gold, at least to an extent significantly greater than background $(P<0.001)$, but much less than the density over the pirellulosome. Possible RNA species contributing to any labelling could be rRNA before or after incorporation into ribosomes, mRNA or tRNA. The 10-fold difference in labelling over the pirellulosome compared with the cap suggests that the translation
Table 2. ds/ssDNA-gold label intensity

\begin{tabular}{|lcc|}
\hline Location & \multicolumn{2}{c|}{ Intensity (particles $\mu^{-2} \pm$ SEM) } \\
\cline { 2 - 3 } & Test & Control \\
\hline Nucleoid & $1073 \pm 27$ & $150 \pm 13$ \\
Pirellulosome & $13 \cdot 0 \pm 2 \cdot 1$ & $6 \cdot 0 \pm 1 \cdot 1$ \\
excluding nucleoid & $1 \cdot 0 \pm 0 \cdot 06$ & $2 \cdot 0 \pm 0 \cdot 13$ \\
Background & \\
\hline
\end{tabular}

apparatus is contained within the pirellulosome, and excluded from the polar region. This is consistent with the occurrence of electron-dense particles of a size compatible with ribosomes only within the pirellulosome. Such compartmentalization of translation is known to occur only in eukaryotic cells (Darnell et al., 1990). If this is so, the small amount of polar cap RNA would not be likely to be ribosomal, and its nature is problematic. The presence of this RNA is consistent with the cap region comprising true cytoplasm rather than a periplasmic or cell wall extension. When DNA was localized using an antibody that visualizes $\mathrm{ds}$ - and ssDNA, the fibrillar nucleoid within the pirellulosome was heavily labelled (Table 2; Fig. 3b). Pre-treatment with enzymes removing specific reactive nucleic acid sites should decrease labelling with RNAse-gold or antids/ssDNA antibody, acting as a control on specificity of labelling. RNAse and DNAse dramatically decreased the level of labelling with RNAse-gold or anti-ds/ ssDNA antibody respectively (Tables 1 and 2).

\section{Implications for prokaryotic cell organization, polar cell differentiation and evolutionary biology}

Thus, the pirellulosome is a membrane-bounded compartment of Pirellula species which compartmentalizes the genomic DNA of the cell, separating it from a second, non-DNA containing region of the cell, the polar cap region. This second compartment contains some RNA, but the major proportion of the cell's RNA appears to be confined to the pirellulosome. In addition to RNA, the polar cap region contains a ruthenium red and phosphotungstic acid/tannic acid/uranyl acetatestainable material which may be a polysaccharide or an unconventional glycoprotein. The pirellulosome appears to be bound continuously by a single membrane separating it from the rest of the cell (the polar cap region). This implies that since the pirellulosome contains the chromosomal DNA, there must be a transport mechanism for transfer of polar cap region components across this pirellulosome membrane. This could be analogous to those which must act in $G$. obscuriglobus with its double-membrane-bounded nucleoid and that are well-established in nucleated eukaryotic cells.

In light of our findings relating to the pirellulosome, we can now state that membrane-bounded DNA-contain- 
ing regions have now been found to occur in two distinct genera of planctomycetes, Pirellula and Gemmata. However, the region in Pirellula differs from that in Gemmata in that it is apparently bounded only by a single membrane, while the nuclear body region of $G$. obscuriglobus is bounded by two membranes separated by an electron-transparent space (Fuerst \& Webb, 1991). In other ways the pirellulosome and nuclear body are similar, in that both contain the nucleoid and all of the cell DNA, and both contain electron-dense ribosomelike particles, in some cases arranged in a linear fashion along the inside surface of the bounding membrane or membranes. The nucleoid in cells of both genera appears to be relatively condensed, even after cryotechniques which should prevent artefactual condensation. However, the cell structure of Pirellula species differs from that of G. obscuriglobus in the concentration of RNA within the pirellulosome relative to a more even distribution of RNA both inside and outside the nuclear body of G. obscuriglobus (unpublished results). A polar cap and polar cap region do not appear in $G$. obscuriglobus, at least not as an asymmetrically distributed area, and the region external to the nuclear body appears to contain electron-dense ribosome-like particles, unlike the apparently ribosome-free polar cap region external to the pirellulosome of Pirellula species. An apparent connection of nuclear body membrane of G. obscuriglobus with other cell membrane is sometimes seen, explaining a possible origin from cytoplasmic membrane in-folding, but such connections have not been seen with the pirellulosome membrane.

The polar caps of P. marina and P. staleyi, a corollary of the possession of pirellulosomes, may be seen as a further example of polar differentiation known to occur already with other structures in these species. Crateriform structures occur only at the reproductive pole, the exact distribution varying with the species (Schlesner, 1986; Schlesner \& Hirsch, 1984); in P. staleyi, at least, the attachment pole, by which cells in rosettes are joined for instance, is slightly pointed, and the flagellum position is at the reproductive cell pole; a holdfast is positioned at the pointed cell pole (Schlesner \& Hirsch, 1984). The exact relationship of the internal cap to these other structures has yet to be determined, but there are some indications that the cap is more common at the budding pole, at least from evidence derived from thin sections of cryofixed cells. However, budding is not necessarily connected with the polar cap, since buds have been observed from either cell pole. Since in negative stain preparations budding occurs often from a slightly sub-polar position, it is difficult to unequivocally determine the relation between caps and budding. It is often difficult to determine the position of the tapered pole in freeze-fracture/etch and negatively stained preparations, where crateriform structures and buds are most easily seen, relative to thin sections, in which the narrow pole is more clearly distinguished. Where rosettes are visible in thin section, the tapered ends of the cells containing caps are at the centre of the rosette (Fig. $3 \mathrm{c})$. This may indicate that some form of holdfast is correlated with the position of the polar cap. The nature of the rosette, however, in relation to its mode of initiation is not clear, since there is evidence that some rosettes may represent the result of multiple budding (Fig. 3d), rather than an aggregation of cells due to holdfasts thought to account for rosettes of Pirellula and Pirellula-like bacteria (Tekniepe et al., 1981; Staley et al., 1992). In Fig. 3(d), the cells involved in the centre of the rosettes display continuity between their cytoplasms and the polar cap pole of the mother cell, rather than a superficial attachment via holdfast material. Both buds exhibit septa involving in-folding of the cell walls of both mother cell and daughter bud.

The pirellulosome appears to be a unique organelle not previously reported in other bacteria, the most similar structure being the membrane-bounded nuclear body of G. obscuriglobus, which is surrounded by two membranes rather than a single membrane. Compartmentalization of cell cytoplasm within separated membrane-bounded regions is a feature of septation in bacteria displaying binary fission, formation of the forespore during sporulation in some Gram-positive bacteria such as Bacillus, formation of the unique 'holdfast' cells of filamentous segmented bacteria in the murine ileum with potential to form spores (Chase \& Erlandsen, 1976) and in the proteobacterium Nitrosolobus (Watson et al., 1971). Both septation and Nitrosolobus compartmentalization involve cell wall infolding, unlike the compartmentalization in Pirellula species. All Nitrosolobus intracellular compartments contain DNA, while only the pirellulosome does in Pirellula species. An analogy with the forespore stage of the bacterial endospore is not likely since there is DNA only in the pirellulosome, the pirellulosome is bounded by a single membrane only, and there is no evidence of engulfment, in-folding of cytoplasmic membrane, or more layers other than the single membrane around the pirellulosome. There is also no evidence for any fully developed spore structures separate from the mother cell or within the mother cell; no pirellulosomes are seen independent of cells within which they occur. The type of compartmentalization in Pirellula also differs from that associated with the periseptal annulus, an organelle separating the division site from the rest of the cell envelope in Gram-negative bacteria (MacAlister et al., 1983). Although it is associated with biochemical as well as morphological compartmentalization of the periplasmic space in Gram-negative bacteria (Foley et al., 1989), it is wholly confined to the periplasm and cell envelope, and does not compartmentalize the cytoplasm.

The polar intracellular organelles known as 'polar membranes' or 'polar organelles' occurring in spiral bacteria such as Rhodospirillum spp. (Hickman \& Frenkel, 1965; Cohen-Bazire \& Kunisawa, 1963) and in Methylomonas (De Boer \& Hazeu, 1972), are completely distinct in nature from the polar cap and polar cap regions described here, since they appear to be brackets closely associated with the cytoplasmic membrane and much smaller. 
Our findings concerning polar differentiation in planctomycetes can be viewed within the perspective of increasing recent interest in the basis for polar differentiation in other bacteria, including especially studies on Caulobacter crescentus but also studies on Bacillus subtilis (Gober \& Marques, 1995; Arigoni et al., 1995). A freshwater planctomycete (ATCC 35122) with polar crateriform structure distribution similar to $P$. staleyi, and classified as a strain of the same species (Starr et al., 1983), has been shown to exhibit a life-cycle involving liberation of swarmer cells in some respects similar to that of C. crescentus, a model for cellular differentiation in prokaryotes (Tekniepe et al., 1981). The cellular differentiation into stalked and swarmer cell types in C. crescentus involves asymmetric protein positioning so that flagellar components, methyl-accepting chemotaxis receptors, and pili are directed to the incipient swarmer pole (the pole opposite to that of the stalk) (Gober $\&$ Marques, 1995). In E. coli, the Tsr, CheA and CheW proteins of the chemotaxis machinery can actually colocalize in inclusion bodies at one pole if a plasmidborne $t s r$ gene lacking both transmembrane domains is expressed (Maddock \& Shapiro, 1993). Targeting of other types of protein to cell poles has also been reported in other bacteria, such as a haemagglutinin in Myxococcus xanthus (Nelson et al., 1981) and a specific protein IcsA in Shigella flexneri (Goldberg et al., 1993).

Since asymmetric localization of individual proteins and protein complexes to a cell pole occurs in diverse bacteria, it is not unreasonable that in some cases polar distribution of larger regions of cytoplasm might occur, perhaps initiated by the type of protein localization in membranes occurring with chemotaxis proteins in $E$. coli and C. crescentus. Such distribution may be similar to formation of inclusion bodies during co-localization with proteins lacking transmembrane domains.

The compartmentalization displayed by cells of Pirellula species may serve as a useful experimental model for polar differentiation at the ultrastructural level. The investigation of the molecular mechanisms of such easily measured differentiation may illuminate other studies where asymmetric localization of selected sets of molecules rather than of intracellular structures visible at the electron microscopic level of resolution correlates with cell differentiation events.

Occurrence of an internal membrane-bounded cell compartment, and especially a compartment wholly containing the genomic DNA, within two distinct genera of planctomycetes, Pirellula and Gemmata, may be significant within an evolutionary context. It is conceivable that membrane-bounded DNA-containing compartments were invented in a common ancestor of these phylogenetically related genera. The original compartment structure may then have become modified in one or both genera by acquisition or loss of one bounding membrane, and by modification of composition and function of the extra-nuclear compartment. In G. obscuriglobus, unlike Pirellula, RNA is distributed throughout the whole cell rather than being concentrated within the membrane-bounded intracellular compartment, as judged from immunocytochemistry (unpublished results). Due to the close phylogenetic relationship between the genera as members of a distinct planctomycete phylum, it seems unlikely that cell compartmentalization in each genus arose independently via convergent evolution. The pirellulosome may form another model, along with the nuclear body of $G$. obscuriglobus, for how an organelle which may have been ancestral to the eukaryotic nucleus could have first arisen within a prokaryotic cell.

\section{ACKNOWLEDGEMENTS}

This research was supported by the Australian Research Council. We thank Staffan Kjelleberg for helpful discussions and Joan Hendrikz for statistical advice.

\section{REFERENCES}

Afzelius, B. A. (1992). Section staining for electron microscopy using tannic acid as a mordant : a simple method for visualization of glycogen and collagen. Microsc Res Tech 21, 65-72.

Arigoni, F., Pogliano, K., Webb, C., Stragier, P. \& Losick, R. (1995). Localization of protein implicated in establishment of cell type to sites of asymmetric division. Science 270, 637-640.

Chase, D. G. \& Erlandsen, S. L. (1976). Evidence for a complex life cycle and endospore formation in the attached filamentous, segmented bacterium from murine ileum. J Bacteriol 127, 572-583.

Cohen-Bazire, G. \& Kunisawa, R. (1963). The fine structure of Rhodospirillum rubrum. J Cell Biol 16, 401-419.

Darnell, J., Lodish, H. \& Baltimore, D. (1990). Molecular Cell Biology, 2nd edn. New York: Scientific American.

De Boer, W. E. \& Hazeu, W. (1972). Observations on the fine structure of a methane-oxidizing bacterium. Antonie Leeuwenboek 38, 33-47.

Ebersold, H. R., Cordier, J. L. \& Lüthy, P. (1981). Bacterial mesosomes: method dependent artifacts. Arch Microbiol 130, 19-22.

Foley, M., Brass, J. M., Birmingham, J., Cook, W. R., Garland, P. B., Higgins, C. F. \& Rothfield, L. I. (1989). Compartmentalization of the periplasm at cell division sites in Escherichia coli as shown by fluorescence photobleaching experiments. Mol Microbiol 3, 1329-1336.

Fuerst, J. A. \& Webb, R. I. (1991). Membrane-bounded nucleoid in the eubacterium Gemmata obscuriglobus. Proc Natl Acad Sci USA 88, 8184-8188.

Gober, J. W. \& Marques, M. V. (1995). Regulation of cellular differentation in Caulobacter crescentus. Microbiol Rev 59, 31-47.

Goldberg, M. B., Barzu, O., Parjot, C. \& Sansonetti, P. J. (1993). Unipolar localization and ATPase activity of IcsA, a Shigella flexneri protein involved in intracellular movement. J Bacteriol 175, 2189-2196.

Graham, L. L. (1992). Freeze-substitution studies of bacteria. Electron Microsc Rev 5, 77-103.

Hayat, M. A. (1991). Stains and cytochemical methods. New York: Plenum Press. 
Hickman, D. D. \& Frenkel, A. W. (1965). Observations on the structure of Rhodospirillum rubrum. J Cell Biol 25, 279-291.

Hobot, J. A., Villiger, W., Escaig, J., Maeder, M., Ryter, A. \& Kellenberger, E. (1985). Shape and structure of nucleoids observed on sections of ultrarapidly frozen and cryosubstituted bacteria. $J$ Bacteriol 162, 960-971.

Kellenberger, E. (1991a). The potential of cryofixation and freeze substitution: observations and theoretical considerations. $J$ Microsc 161, 183-203.

Kellenberger, E. (1991b). Functional consequences of improved structural information on bacterial nucleoids. Res Microbiol 142, 229-238.

Kellenberger, E. \& Arnold-Schulz-Gahmen, B. (1992). Chromatins of low-protein content: special features of their compaction and condensation. FEMS Microbiol Lett 100, 361-370.

König, H., Schlesner, H. \& Hirsch, P. (1984). Cell wall studies on budding bacteria of the Planctomyces/Pasteuria group and on a Prosthecomicrobium sp. Arch Microbiol 138, 200-205.

Liesack, W., König, H., Schlesner, H. \& Hirsch, P. (1986). Chemical composition of the peptidoglycan-free cell envelopes of budding bacteria of the Pirella/Planctomyces group. Arch Microbiol 145, 361-366

Liesack, W., Söller, R., Stewart, T., Haas, H., Giovannoni, S. \& Stackebrandt, E. (1992). The influence of tachytelically (rapidly) evolving sequences on the topology of phylogenetic trees intrafamily relationships and the phylogenetic position of Planctomycetaceae as revealed by comparative analysis of $16 \mathrm{~S}$ ribosomal RNA sequences. Syst Appl Microbiol 15, 357-362.

Lindsay, M. R., Webb, R. l., Hosmer, H. \& Fuerst, J. A. (1995). Effects of fixative and buffer on morphology and ultrastructure of a freshwater planctomycete, Gemmata obscuriglobus. J Microbiol Methods 21, 45-54.

MacAlister, T. J., Macdonald, B. \& Rothfield, L. I. (1983). The periseptal annulus: an organelle associated with cell division in Gram-negative bacteria. Proc Natl Acad Sci USA 80, 1372-1376.

Maddock, J. R. \& Shapiro, L. (1993). Polar location of the chemoreceptor complex in the Escherichia coli cell. Science 259, 1717-1723.

Nelson, D. R., Cumsky, M. G. \& Zusman, D. R. (1981). Localization of myxobacterial haemagglutinin in the periplasmic space and on the cell surface of Myxococcus xanthus during developmental aggregation. J Biol Chem 256, 12589-12595.

Ryter, A. (1988). Contribution of new cryomethods to a better knowledge of bacterial anatomy. Ann Inst Pasteur (Paris) 139, $33-44$.

Schlesner, H. (1986). Pirella marina sp. nov., a budding, peptidoglycan-less bacterium from brackish water. Syst Appl Microbiol 8, 177-180.
Schlesner, H. \& Hirsch, P. (1984). Assignment of ATCC 27377 to Pirella gen. nov. as Pirella staleyi comb. nov. Int J Syst Bacteriol 34, 492-495.

Schlesner, H. \& Stackebrandt, E. (1986). Assignment of the genera Planctomyces and Pirella to a new family Planctomycetaceae fam. nov. and description of the order Planctomycetales ord. nov. Syst Appl Microbiol 8, 174-176.

Stackebrandt, E., Fischer, A., Hirsch, P., Roggentin, T. \& Schlesner, H. (1986a). The phylogeny of an ancient group of budding peptidoglycan-less eubacteria: the genera Planctomyces and Pirella. Endocytobiosis Cell Res 3, 29-40.

Stackebrandt, E., Wehmeyer, U. \& Liesack, W. (1986b). $16 \mathrm{~S}$ ribosomal RNA- and cell wall analysis of Gemmata obscuriglobus, a new member of the order Planctomycetales. FEMS Microbiol Lett 37, 289-292.

Staley, J. T. (1973). Budding bacteria of the Pasteuria-Blastobacter group. Can J Microbiol 19, 609-614.

Staley, J. T., Fuerst, J. A., Giovannoni, S. \& Schlesner, H. (1992). The order Planctomycetales and the genera Planctomyces, Pirellula, Gemmata and Isosphaera. In The Prokaryotes: a Handbook on the Biology of Bacteria: Ecophysiology, Isolation, Identification, Applications, 2nd edn, vol. IV, pp. 3710-3731. Edited by A. Balows, H. G. Trüper, M. Dworkin, W. Harder \& K.-H. Schleifer. New York: Springer-Verlag.

Starr, M. P., Sayre, R. M. \& Schmidt, J. M. (1983). Assignment of ATCC 27377 to Planctomyces staleyi sp. nov. and conservation of Pasteuria ramosa Metchnikoff 1888 on the basis of type descriptive material. Int J Syst Bacteriol 33, 666-671.

Takagi, M., Parmley, R. T., Denys, F. R. \& Kageyama, M. (1983). Ultrastructural visualization of complex carbohydrates in epiphyseal cartilage with the tannic acid-metal salts method. I Histochem Cytochem 31, 783-790.

Tekniepe, B. L., Schmidt, J. M. \& Starr, M. P. (1981). Life cycle of a budding and appendaged bacterium belonging to morphotype IV of the Blastocaulis-Planctomyces group. Curr Microbiol 5, $1-6$.

Ward, N., Rainey, F. A., Stackebrandt, E. \& Schlesner, H. (1995). Unraveling the extent of diversity within the order Planctomycetales. Appl Env Microbiol 61, 2270-2275.

Watson, S. W., Graham, L. B., Remsen, C. C. \& Valois, F. W. (1971). A lobular, ammonia-oxidizing bacterium, Nitrosolobus multiformis nov. gen. nov. sp. Arch Mikrobiol 76, 183-203.

Woese, C. R. (1987). Bacterial evolution. Microbiol Rev 51, 221-271.

Received 22 July 1996; revised 28 October 1996; accepted 29 October 1996. 